\title{
Rebuttal of Martin-Silverstone et al. 2017, 'Reassessment of Dawndraco kanzai Kellner 2010 and reassignment of the type specimen to Pteranodon sternbergi Harksen, 1966'
}

\author{
Alexander W. A. Kellner
}

Laboratory of Systematics and Taphonomy of Fossil Vertebrates, Department of Geology and Paleontology, Museu Nacional/UFRJ, Rio de Janeiro, RJ, Brazil; kellner@mn.ufrj.br

There are well over a thousand specimens of the flying reptile Pteranodon or, as I prefer to call it, the Pteranodoncomplex (Kellner 2010). The material comes from the Smoky Hill Chalk Member of the Niobrara Formation (late Coniacian - early Campanian, Hattin 1982) and the Sharon Springs Formation (middle Campanian, Martin et al. 2007) of the Pierre Shale Group. The temporal range of the pterosaur occurrences in these units certainly extend for over four million years (Bennett 1992), particularly if the Sharon Springs Formation is taken into consideration. Sadly, there is no accurate stratigraphic data for most fossils (Miller 1972, Bennett 1994). Thus, in some cases, one could end up comparing individuals that have lived millions of years apart, a common situation in paleontological studies (e.g., Pinheiro and Rodrigues, 2017).

Known since the latter part of the 19th century, there have been several taxonomic reviews of this pterosaur material, most recognizing multiple species (e.g., Eaton 1910, Miller 1972, Schoch 1984), sometimes even including Nyctosaurus, which is nowadays regarded as belonging to a distinct clade (e.g., Bennett 1994, Kellner 2003, Andres et al. 2014). The most comprehensive reviews of the Pteranodon-complex were done by Bennett (1992, 1993, 1994, 2001), who recognized only two species: Pteranodon sternbergi, smaller and restricted to the lower section of the Smoky Hill Chalk Member of the Niobrara Formation, and Pteranodon longiceps, larger and occurring in the upper section of the Smoky Hill Chalk Member and in the overlying Sharon Springs Formation (Bennett 1992, 1994). These did not overlap stratigraphically and, according to Bennett (1992), both were sexually dimorphic, an interpretation that he still maintains (Bennett and Penkalski 2017).

Published August 11, 2017

(c) 2017 by the author

submitted February 2, 2017; accepted May 8, 2017

This article is part of a comment/response submission and therefore is not peer-reviewed.

Handling editor: Robert Holmes
Among the several specimens of the Pteranodon-complex that I have examined, one of the most outstanding is the fairly complete skeleton UALVP 24238 (Fig. 1 A), which has been briefly illustrated and referred to Pteranodon sternbergi by Bennett (1992, 1994, 2001). Based on the several morphological differences between UALVP 24238 and the holotype of Pteranodon sternbergi (FHSM VP 339, that has been previously referred to the genus Geosternbergia by Miller 1972, 1978; Fig. 1B), I came to a different conclusion, ending up establishing the taxon Dawndraco kanzai (Kellner 2010).

Recently, Martin-Silverstone et al. (2017) disagreed with my interpretation, and reassigned UALVP 24238 to Pteranodon sternbergi. Due to the importance of this debate for pterosaur research in general, as noted by these authors, I decided to challenge their analysis which shows some misconceptions about pterosaur ontogeny, different interpretation of what was actually said about Pteranodon, and contains in some parts indication of circular reasoning. I will not discuss all our divergences, but concentrate on the most significant ones. For clarity, I will avoid using taxonomic names for much of this discussion and will refer to the collection numbers UALVP 24238 for Dawndraco kanzai and FHSM VP 339 for Geosternbergia sternbergi, regarded by them (and by Bennett 1992) as conspecific. As odd as it might sound, there is much agreement between my study (Kellner 2010) and the one presented by Martin-Silverstone et al. (2017), which I will briefly summarize below.

We agree that UALVP 24238 is an exceptional specimen, one of the best pteranodontid pterosaurs from North America and that it has always deserved a detailed description. I provided some information about this specimen, mainly focusing on the skull (Kellner 2010) and MartinSilverstone et al. (2017) followed up with a more detailed account. Having said that, I would like to add that much more could be done, including the preparation of the pelvis that could provide interesting points regarding the gender discussion (see appropriate section below). 
We both acknowledge that there is little stratigraphic data for the pteranodontid material in general. We all note that the majority of the specimens are disarticulated or consist of articulated forelimbs alone, and that they are generally crushed and distorted, despite the fact that the bone surface tends to be well preserved (Bennett 1994).

We also agree that the frontal crest in UALVP 24238 had a comparatively short base, its anterior margin aligning with the anterior margin of the orbit. During my study, I established that the basal portion of the crest of this specimen was not extended and therefore this individual did not have had a broad crest as the one of FHSM VP 339, but entertained the possibility that this cranial structure could have been much longer, somewhat similar to Pteranodon longiceps, which still cannot be ruled out. Martin-

Silverstone et al. (2017) revealed that the reconstruction of the small crest present on the display of this skeleton was made aiming to replicate the information retrieved from the field, something I did not know. If UALVP 24238 had had such a small crest, than it would be even more distinct than I originally anticipated.

Both studies accept that a premaxillary crest cannot be identified in UALVP 24238 (contra Bennett 1992 and Bennett and Penkalski 2017), although Martin-Silverstone et al. (2017) mention that the crest might be difficult to recognize. Overall, we tend to agree with morphologicaldetails of this material and acknowledge that several cranial and postcranial elements are fused.

Regarding disagreements, I have organized them in topics as a matter of clarity.

\section{MALE VERSUS FEMALE}

Martin-Silverstone et al. (2017) have pointed out that UALVP 24238 was identified by Bennett (1992) as a male against my deduction that it had been regarded as a female (Kellner 2010). In fact, except for a sketch apparently based on two specimens of P. longiceps, Bennett (1992) never explicitly identified any Pteranodon skull in his drawings as representing a male or a female, including UALVP 24238 and FHSM VP 339. In a recent paper, to which Martin-Silverstone et al. (2017) had access before it was published, Bennett and Penkalski (2017) specifically stated that in mature males such as UALVP 24238, the depth of the rostrum was increased by a prominent premaxillary crest. Although such a crest cannot be identified in UALVP 24238 (Kellner 2010, Martin-Silverstone et al., 2017) or in the large and potentially male represented by FHSM VP 339, this statement shows that I misinterpreted the information published by Bennett (1992).
Despite some lack of clarity in his illustrations regarding the identification of males and females, Bennett (1992) has stated that, besides the pelvis (see comments below), sexual dimorphism in these pterosaurs is revealed by the size and extension of their cranial crest. According to him, males show a large frontal crest with an anteroposterior longer base, while in females this cranial structure would be much smaller, with a comparatively shorter anteroposterior base, what is exactly the condition of UALVP 24238 (Fig. 1). He also presented a general reconstruction of a male and a female Pteranodon longiceps (Bennett 1992, fig. 3), a pattern that is somewhat replicated in the subsequent illustrations of the skulls he choose to figure (Bennett 1992, figs. 4 and 5). Specifically illustrating "Pteranodon" sternbergi, Bennett (1992, fig. 5) showed only two skulls of that species: UALVP 24238 , reproduced as having a small crest, while FHSM VP 339 was reproduced as having a large crest, what is consistent with the main differences between males and females he discussed in the text. Therefore, this invites the interpretation of one being a female and the other a male, as I did (Kellner 2010). It is also interesting to mention that

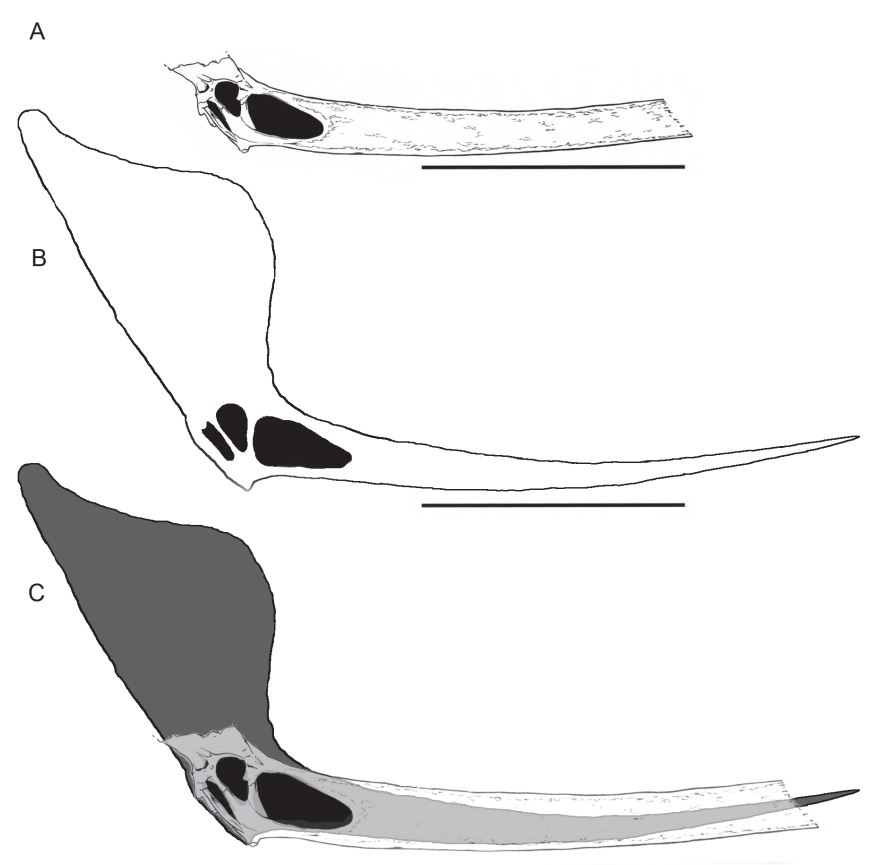

Figure 1. Comparisons of the skulls of UALVP 24238 (holotype of Dawndraco kanzai) and FHSM VP 339 (holotype of Geosternbergia sternbergi), in lateral view: $A$, drawing of UALVP 24238; B, outline of FHSM VP 339 (reversed); C, superimposition of UALVP 24238 over FHSM VP 339. In C, orbits and nasoantorbital fenestra were used as landmarks and forced to fit, resulting in an increase of UALVP 24238 in about $26 \%$ of its original size. A, after Kellner (2010) and B, redrawn from Bennett (1994). Scale bar of $A$ and $B=500 \mathrm{~mm}$. 
the wingspan of the modal Niobrara pterosaur female (Bennett 1992: $3.8 \mathrm{~m}$ ) was quite similar to the wingspan estimated by Martin-Silverstone et al. (2017) for UALVP $24238(4 \mathrm{~m})$. I am not aware of any other illustrated skull that might reflect the purported differences in males and females of this species ("P." sternbergi), something that is expected in a paper describing sexual dimorphism where differences in the cranial crest are argued.

In any case, it was not the male or female issue that led me to propose a new taxon for UALVP 24238, but the morphological differences that exist between this specimen and other pteranodontids, including FHSM VP 339 (see below). Actually, if I had not been mislead, I would have seriously questioned how two mature males of the same species can show so many morphological differences (see Fig. 1), what strengthen the case that they belong to different taxa. Still regarding the male versus female debate, MartinSilverstone et al. (2017) took note about the bimodal pattern recovered by Bennett (1992). However, bimodality alone might not provide definite signal for sexual dimorphism (e.g., Olson 1957). Recognizing this, Bennett (1992) relied on morphology for gender differentiation, in this case mainly the extension of the puboischiadic plate. This notion of sexual dimorphism was than used to interpret the differences in the cranial crest morphology of pterosaurs (Bennett 1992). To my knowledge, there are no figured specimens of Pteranodon (or related species) combining complete posterior regions of skulls and pelves where argumentation for sexual dimorphism could be made (Kellner and Tomida 2000). Perhaps, further preparation of the pelvic region of UALVP 24238, combined with some alternative ways of assessing the size of the pelvic canal in flattened material (e.g., 3-D reconstruction based on CT-scans) might help in this matter (see discussion in Cheng et al. 2017). To further demonstrate difficulties of gender differentiation within pterosaurs, although Bennett (1992) considered the possibility that the anhanguerids Anhanguera and Tropeognathus might represent males and females of the same species, this was latter refuted by both, morphology (Kellner and Tomida 2000) and phylogeny (Kellner 2003, Andres et al. 2014).

Nevertheless, there is some basis for recognizing sexual dimorphism in pterosaurs based on the morphology of their cranial crests. In one of the few pterosaur bonebeds (which include some eggs, demonstrating the likelihood of the presence of females), where different individuals can confidently be assigned to the same species, there are morphological evidences suggesting that the expression of the cranial crests (but not their presence, see Cheng et al. 2017) might be sexually dimorphic (Wang et al. 2014a). In my opinion, this has still to be demonstrated for Pteranodon or Pteranodon-like taxa.

\section{ONTOGENY}

The following question is perhaps the most important issue relating to UALVP 24238: what ontogenetic stage has this individual reached at time of death? There is no question that we still need to learn much more about pterosaur ontogeny, and there might be variations from clade to clade. There are a few points, however, that most "pterosaurologists" would agree: fusion of bones is an important tool to establish if an animal had reached skeletal maturity. Martin-Silverstone et al. (2017) acknowledge that several bones of UALVP 24238 are fused, including elements of the skull, scapulocoracoid, carpals, dorsal vertebrae forming a notarium, tibiotarsus, and the presence of a synsacrum. However, they regard UALVP 24238 as still being a subadult or not yet fully osteologically mature.

Regarding the skull, Martin-Silverstone et al. (2017) said that crushing is one of the reasons why they were not able to identify sutures, which raises the possibility that some cranial elements might not have been fused in UALVP 24238. However, bone surface is generally well preserved in most Pteranodon material (e.g., Bennett 1994). Except for some areas, this is certainly true for UALVP 24238, particularly above the nasoantorbital fenestra and the anterior part of the orbit, where several bones are located (e.g., Bennett 2001). I offer a different explanation for the lack of sutures in the skull: the bones are fused. Sub-adults such as the holotype of the large anhanguerid Anhanguera piscator (Kellner and Tomida 2000), show several unfused elements, but this is not the case here. In animals that have reached or are about to reach full osteological maturity, cranial elements are fused (e.g., Kellner et al. 2013), and in some cases leave a sulcus behind indicating where a suture might have been located (see premaxilla and frontal in UALVP 24238, Kellner 2010). The fusion of cranial elements is regarded as a feature of fully-grown individuals (Bennett 1993), as noted by Martin-Silverstone et al. (2017).

To support their claim for a subadult status of UALVP 24238, even after acknowledging that the fusion of cranial elements is indicative of fully-grown individuals, MartinSilverstone et al. (2017) pointed out the presence of "minimal but obvious pitting" on the apices of the right radius, ulna and forth metacarpal, suggesting incomplete ossification of the epiphysis. This is an interesting observation that has been used to identify osteologically immature individuals in the past (e.g., Bennett 1993). If this is effectively the case (detailed figures would have helped), then it raises another series of questions: why was this "obvious pitting" not found in the first phalanx of the wing fingers (ph1d4), particularly the left one that they claim lacks an extensor tendon process? And what about other bones? 
A second feature used by the authors to support a subadult status of UALVP 24238 is the apparent lack of the left extensor tendon process (etp). I have examined the published pictures and drawings and wonder if this portion of the left ph1d4 is not hidden by the distal articulation of metacarpal IV, with which it is articulated. Oddly, the right ph1d4, that is well exposed, has the etp fused (Kellner 2010), also acknowledged by Martin-Silverstone and colleagues. What do we know about the fusion of the etp and the ph1d4? According to Bennett (1993), these bones are among the last to fuse, shortly before the animal reaches skeletal maturity. I have also made similar observations, although other elements fuse at a latter stage (Kellner 2015). Nevertheless, the fusion of these elements appears to indicate that UALVP 24238 has reached a late ontogenetic stage at time of death.

Lastly, Martin-Silverstone et al. (2017) argued that UALVP 24238 had only five vertebrae fused into a notarium, while it is known that Pteranodon had six (Bennett, 1993). In my notes and recollections of the specimen, I have counted six vertebrae forming the notarium (Kellner 2010), with the last one at least starting to fuse with the preceding element (e.g., transverse processes, part of the neural spine). But let's entertain the possibility of the completely fused elements of the notarium in UALVP 24238 being restricted to five. The number of vertebrae that fuse into a notarium might change throughout ontogeny, but can also potentially represent differences in taxonomy and we cannot confidently assess this possibility in most cases. For example, a specimen of the anhanguerid Tropeognathus cf. T. mesembrinus, which has a maximized wingspan of over eight meters, incorporated five dorsal vertebrae into a notarium and is considered to have had reached skeletal maturity, even if some limited further growth might still have had been possible if the animal had not perished (Kellner et al. 2013).

In my opinion, the osteological features present in UALVP 24238 strongly suggest that it had reached an advanced ontogenetic stage. This seems (and I am very cautious here) also to be the interpretation of Bennett and Penkalski (2017), since they specifically stated UALVP 24238 as a being a mature specimen, a detail not acknowledged by Martin-Silverstone et al. (2017). Of course, this does not exclude the possibility of limited growth if this particular individual had not become available for fossilization due to some unknown misfortune. Lets, however, again entertain the "subadult" or the "at least nearing, but not yet attaining skeletal maturity" hypotheses put forward by Martin-Silverstone et al. (2017). What do they want to imply? Essentially, that UALVP 24238 could have grown substantially more had it not perished. When fully skeletal maturity was reached, it would have had developed a similar large crest and extended rostrum that are present in FHSM VP 339, since they consider them both males of the same species.

Although there might be some flexibility inherent to the term subadult, generally used when the animal has passed the juvenile period but did not yet fully develop typical adult characteristics that also involves growth, the fusion of several cranial and postcranial elements argues against the possibility of much additional growth of UALVP 24238. Furthermore, even taking into consideration the arguments for this specimen not being fully grown, at least for the Pteranodon-complex, same-sized individuals might not have had all bones equally fused, with subadults not much smaller than adults (Bennett 1993). In the ontogenetic series of the tapejarid Cainajara dobruskii, there is a substantial increase of the cranial crest from juveniles to subadults. But very early on their ontogenetic development there is no significant modification in the basic shape and inclination of this cranial structure (Manzig et al 2014). It seems quite unlikely that the crest would develop from the small size present in UALVP 24238 (for all assuming the reconstruction reflects its real shape, as implied by Martin-Silverstone et al. 2017) into the large structure found in FHSM VP 339, a purported male of the same species (Fig. 1 C). To state that the small size of the crest found in UALVP 24238 fits the "growth predictions" for this pterosaur is unsubstantiated and so far undocumented by all evidence published regarding pterosaur cranial osteological and ontogenetic changes that I am aware of. And that includes all papers on the Pteranodon-complex. Perhaps the authors might like to provide such a model in the future.

Considering that the ontogenetic status of UALVP 24238 is paramount for the interpretations of Martin-Silverstone et al. (2017), there is a more precise way to assess the skeletal maturity of this pterosaur: osteohistological sections. There are several studies on fossil bone histology that provided opportunities to assess the ontogenetic status of one individual, even helping with taxonomic decisions (e.g., Padian et al. 2004). Despite the destructive nature of this kind of analysis (perhaps more easily done now since for some, UALVP 24238 might not represent a distinct species anymore), one could sacrifice a small piece of both first wing phalanges and the right wing metacarpal of this material since they are already broken. Midshafts of humeri and femura might even be better, but than, this specimen might turn out to be a new species after all. Here is my prediction: osteohistological sections will find lines of arrested growth and at least some indication of an external fundamental system, showing that substantial growth had already ceased, as observed in ontogenetically mature individuals (e.g., Kellner et al. 2013). If not, this would not be a waste of good pterosaur bones, but provide a critical view of what fused bones can actually 
tell about ontogeny. By the way, I would be more than happy to team up with anyone that would like to engage in such a study and that might put the question of the ontogenetic status of UALVP 24238 to rest.

\section{ROSTRUM}

The most outstanding morphological feature of UALVP 24238 is the rostrum. It is deep and shows subparallel dorsal and ventral margins. A premaxillary sagittal crest is not present, although there seems to be some hesitation by Martin-Silverstone et al. (2017). In order to use an empirical measure to assess the extension of the rostrum that could be compared among all pterosaur taxa, I have introduced an index called the rostral value ( $\mathrm{RV}=$ ros-1/ aen-h). It is defined as the rostral length (ros-l) divided by the height of the anteriormost point of the external naris (or nasoantorbital fenestra - aen-h), where ros-l is measured from the anteriormost point of the external naris (or nasoantorbital fenestra) to the tip of the premaxillae, and aen-h is measured perpendicularly from the ventral margin of the skull to the anteriormost point of the external nares (or nasoantorbital fenestra). Martin-Silverstone et al. (2017) incorrectly regarded this index as being the same as the rostral index of Martill and Naish (2006). Although both indices consider the length of the rostrum, the rostal index measures the total height of the rostrum immediately anterior to the nasoantorbital fenestra (Martill and Naish 2006). Such a measurement is influenced by the presence and dorsal extension of a premaxillary crest, something that I tried to avoid.

Martin-Silverstone et al. (2017) argue that the comparisons between the rostral value of the holotype of Pteranodon longiceps (YPM 1177) and UALVP 24238 are "questionable due to the likelihood" that the rostrum in YPM 1177 might not be complete. However, in YPM 1177 (of which the Museu Nacional has obtained a cast - MN 6953), the upper and lower jaws taper and end essentially at the same point. Except for, perhaps, the most anterior tip of both jaws, there is no indication that anything was lost. The argument of Martin-Silverstone et al. (2017) for the incompleteness of this specimen rests solely on the diagnosis of Bennett (1994) for Pteranodon longiceps, where the upper jaw (premaxillae) is stated to extend beyond the anterior tip of the mandible. One might argue for different reasons why the upper and lower jaws end at the same point in this particular material or even advocate that the comparisons between of UALVP 24238 and the YPM 1177 (the holotype of $P$. longiceps) might not be valid. But denying a morphological feature present on a specimen due to the fact that it does not conform to somebody's diagnosis sounds quite odd, or even troubling, an expression Martin-
Silverstone et al. (2017) like to use.

It should be noted that all published reconstructions of UALVP 24238 (Bennett 1992, 1994, 2001, Kellner 2010, Martin-Silverstone et al. 2017) are in general agreement. Although not being complete, the skull FHSM VP 339 was apparently reconstructed following the outline of the specimen when it was collected (Miller 1972). Despite some caution, this outline is generally accepted as accurate (e.g., Harksen 1966, Miller 1972, Bennett 1992, 1994, 2001, Kellner 2010). By superposing both outlines using the orbit and the nasoantorbital fenestra as landmarks, there is little doubt that the rostra of FHSM VP 339 and UALVP 24238 are very distinct (contra Martin-Silverstone et al. 2017), with the preserved portion of the latter being substantially deeper and more elongate (Fig. 1C). The bony part of the rostral portion of FHSM VP 339 that seems the most reliable portion of the upper jaw in the latest reconstruction presented by Bennett (1994, fig. 5) also shows this difference. Furthermore, there is a distinct difference in the extension of the anterior portion of the crest relative to the orbit in both specimens (Fig. 1C).

\section{DIAGNOSIS}

Martin-Silverstone et al. (2017) do an interesting job of discussing all diagnostic features that I have pointed out to distinguish UALVP 24238 from other pterosaurs. I will not go over each one by one, but note that, although recognizing their existence, they have dismissed them by arguing postmortem distortion or incomplete preservation. In other words, the morphological differences are there, but our interpretations of why they are the way they are differ. Regarding flattened fossils, essentially all changes in morphology can be dismissed and attributed to taphonomic changes, if one choses to do so. It should be noted, however, that in the Pteranodon-complex case, the comparisons were made between pterosaurs that were preserved in the same depositional environment: under low energy and in deep water conditions (Bennett 1994). The material in question was compressed in the same way, with the skulls flattened laterally. Thus, comparisons were made with specimens that have been preserved under the same taphonomic conditions. Although it would be naive not to acknowledge that even in such circumstances differential morphological changes due to preservation are are possible (e.g., elastic as opposed to plastic deformation, skulls compressed over hard parts present on the substrate or over other parts of their skeleton), this does not appear to be the case here. At least at the first order of approximation, it seems not unreasonable to assume that similar changes might have affected skulls that were preserved in a similar way. 
Concerning diagnoses in general, they might change as more information becomes available. Martin-Silverstone et al. (2017) use the diagnosis presented by Bennett (1994) for Pteranodon. Although I do refer the reader to the discussion presented previously (Kellner 2010), just for the sake of argumentation, I will highlight two points regarding the diagnosis employed by them in the taxonomic discussion of UALVP 24238: the presence of a cranial crest made by the frontals directed up and back, and the presence of proximal caudal vertebrae with duplex centra. Cranial crests made by the frontals have since been reported in other pterosaurs such as Guidraco and Ludodactylus (Frey et al. 2003, Wang et al. 2012) and proximal caudals with duplex centra were reported in Anhanguera (Kellner \& Tomida 2000). That said, regarding the cranial crest, a highly controversial topic these days (see Cheng et al. 2017), I hardly believe that Guidraco or Ludodactylus should be classified into the genus Pteranodon, but just would like to stress that diagnoses can change with the advent of new specimens or more information. That seems also to be the case for the Pteranodon-complex.

\section{SPLITTER VERSUS LUMPER}

Regarding my decision to erect a new species for UALVP 24238, Martin-Silverstone et al. (2017: p. 47) stated that: "No phylogenetic analysis is presented, and these decisions appear to represent a preference for taxonomic splitting."

They are correct that I did not present any phylogeny regarding my taxonomic decision on UAVLP 24238 (neither did they, did they?). Taxonomic decisions regarding species do not necessarily need to rest on a phylogenetic analysis, as was also the case for previous taxonomic decisions regarding the specimen discussed here (UAVLP 24238) and others of the Pteranodon-complex (e.g., Bennett 1992, 1994). Similarly, a phylogenetic analysis is not necessary when a specimen is assigned to a pre-existing clade (e.g., Martin-Silverstone et al. 2016).

However, from all arguments presented by MartinSilverstone and colleagues against my interpretation of UALVP 24238, the most surprising one to me was the splitter label. Am I a splitter, perhaps boosting up diversity where there is none? Looking back on some of my taxonomic decisions, I was involved with my colleague Diogenes Campos in a project that has regarded the anhanguerid Tropeognathus congeneric with Anhanguera (Kellner and Campos 1988), a decision that proved to be partially correct (Kellner and Tomida 2000, Andres et al. 2014). Again with Campos, when describing a tapejarid from the Early Cretaceous Crato Formation, I initially "lumped" the species now known as Tupandactylus imperator (Kellner and Campos 2007) with the genus Tapejara (Campos and Kellner 1997). Not to mention that I went a great length to provide information about some Chinese pterosaurs in exactly the same publication where I decided on UAVLP 24238, discussing why I agreed that Huaxiaperus jii should be synonymized (or "lumped") with Sinopterus dongi (Kellner 2010). Does this make me a "lumper", that might not recognize true diversity and unites different species into the same one what has several undesired consequences (e.g., biogeography)?

I do not have any particular preference when it comes to taxonomic decisions. I have previously discussed the difficulties of species recognition in pterosaurs (that could be applied to other vertebrates as well), which have resulted in disagreement among researchers (Kellner 2010), and I will not repeat it here. As a matter of fact, I do feel that the pterosaur diversity does not suffer from oversplitting, but perhaps rather from overlumping. And this does not reflect any preference of mine. For example, several species previously regarded as belonging to the Eudimorphodon-complex (first pointed out by Kellner 2003) and Pterodactylus of Solnhofen are now placed in different genera (e.g., Dalla Vecchia 2009, Vidovic and Martill 2017). Older collections have been revisited and apparently also show more diversity than originally thought (e.g., Hone et al. 2017). And this does not seem to be related to a new and general trend of typological oversplitting.

Nonetheless, as I have stressed before (Kellner 2010), morphology is crucial for establishing or synonymizing species. Granted, as happens at present, there should be plenty of individual variation within members of a single species for several reasons (e.g., ontogeny, food resources). It is also possible that pterosaurs (or some of them) showed marked sexual dimorphism that would be expressed not only by the soft tissue morphology (e.g., different colors of pycnofibers, colorful soft tissue extensions on cranial crests), but also in the skeleton. We expect that because it is observed nowadays when studying individuals of populations that can be confidently assigned to the same species. And here resides the problem with pterosaurs (and most other fossil vertebrates): the lack of populations that might reflect the same species in the fossil record!

Concerning pterosaurs, there are only three bonebeds available (e.g., Chiappe et al. 1998, Chiappe et al. 2000, Codorníu and Chiappe 2004), two of which were discovered a few years ago and have not yet been studied in detail (Wang et al. 2014a, Manzig et al. 2014). All are predominantly monospecific and none shows pterosaur cranial material with so many morphological differences as observed between UALVP 24238 and FHSM VP 339 (Fig. 1C). These differences have now even become more significant since apparently sexual dimorphism was ruled out (MartinSilverstone et al. 2017, Bennett and Penkalski 2017). 
Regarding stratigraphy, as correctly pointed out by Martin-Silverstone et al. (2017), I have called attention to the fact that, according to Bennett (1994), UALVP 24238 and FHSM VP 339 come from different stratigraphic levels; but this was not the primary justification for the separation of these specimens in different species - morphology was. As I have pointed out before (Kellner 2010), morphology $(\mathrm{M})$ is the main aspect to be considered, but stratigraphy $(S)$ and, to a lesser extent geography $(G)$, are also part of the equation (MSG). Bennett (1992) mentioned that the specimens of the Pteranodon-complex were collected in deposits formed some $200 \mathrm{~km}$ away from the ancient Cretaceous shorelines. This potentially could have restricted diversity (i.e., smaller species might not have been able to fly so far away, not considering biostratinomy). Even keeping this potential preservation bias in mind, the occurrence of a higher number of flying reptile species in this stratigraphic section is not inconceivable, particularly taking into account that two formations representing over 4 million years, whose outcrops spans over a considerable geographic area, are involved. If one takes the Jehol Biota of China as an example, although agreeing that the number of species might be inflated (e.g., Wang et al. 2005, Wang and Zhou 2006, Kellner 2010, but see Andres et al. 2014), there is a tremendous amount of diversity, even if only considering the Aptian Jiufotang Formation (e.g., Wang et al. 2005, Lü and Ji, 2006, Lü et al. 2008, Wang et al. 2012, Wang et al. 2014b, Andres et al. 2014). Since it seems quite implausible that all these pterosaurs came from the same horizon (no pterosaur bonebed regarding this deposit is known) or represent species that cohabited the same area during the same time, one compelling (but admittedly speculative) explanation that might explain this diversity is that fossils come from different layers. It appears that taphonomic and paleoenvironmental conditions of the Jiufotang deposits (and perhaps other similar ones in China) might have resulted in "sampling" of the biota during different times along some million years. However, as with the Pteranodon-complex, there is not enough stratigraphic data to support this hypothesis, but the point here is that stratigraphy should not be dismissed a priory and can be argued to back morphology.

\section{FINAL COMMENTS}

I do not cherish any illusions that these lines will settle the question regarding the taxonomic status of UALVP 24238 and FHSM VP 339, which I consider to represent distinct taxa, Dawndraco kanzai and Geosternbergia sternbergi, respectively (Kellner 2010). This view is even more strengthened now that sexual dimorphism was apparently excluded. Even if UALVP 24238 represents an ontogenetically younger animal then I had thought, there are still lots of differences in morphology that cannot be dismissed by general statements such as "difficult to measure", "postmortem distortion", and "incomplete preservation". This kind of argument can be used for rejecting almost any morphological difference in non-3D specimens.

However, contrary to most disputes over taxonomical issues, the present one might be solved quite easily with osteohistological sections. Such a study will give us a better understanding of the growth potential that was still left for UALVP 24238 at time of death, shedding some needed light on the "male hypothesis" regarding this specimen.

I have not discussed the diversity of cranial material of the Pteranodon-complex presently available for study, but based on UALVP 24238 (and another skull, see Kellner 2010), I argue that there is more taxonomic diversity than currently admitted by Bennett $(1994,2001)$ and Martin-Silverstone et al. (2017). If the remarkable variation in cranial morphology presented by these purported males, where the smaller one (UALVP 24238), albeit having reached an advanced ontogenetic state (at least 0S5 of Kellner 2015), shows so many differences from the larger (FHSM VP 339) and still both represent the same species, it might just be very hard to tell pterosaurs apart.

Lastly, I am afraid that achieving a so called "solid foundation of pterosaur science" might, unfortunately, be still some time away. Perhaps this may be best accomplished by keeping open-minded about different ideas and try to test them.

\section{ACKNOWLEDGEMENTS}

I wish to thank Alison Murray for granting the possibility to respond to Martin-Silverstone et al. (2017) and Robert Holmes for editorial suggestions. Along the years, I profited from several discussions with several colleagues about pterosaur ontogeny and sexual dimorphism - too many to list here. Founding for my research comes from the Conselho Nacional de Desenvolvimento Científico e Tecnológico CNPq, (CNPq \# 304780/2013-8 and the Fundação Carlos Chagas Filho de Amparo a Pesquisa do Estado do Rio de Janeiro (FAPERJ \# E-26/202.893/2015).

\section{LITERATURE CITED}

Andres B., J. Clark and X. Xu. 2014. The earliest pterodactyloid and the origin of the group. Current Biology 24:1011-1016.

Bennett, S.C. 1992. Sexual dimorphism in Pteranodon and other pterosaurs, with comments on cranial crests. Journal of Vertebrate Paleontology 12:422-434. DOI 10.1080/02724634.1992.10011472 
Bennett, S.C. 1993. The ontogeny of Pteranodon and other pterosaurs. Paleobiology 19:92-106. DOI 10.1017/ S0094837300012331

Bennett, S.C. 1994. Taxonomy and systematics of the Late Cretaceous pterosaur Pteranodon (Pterosauria, Pterodactyloidea). Occasional Papers of the Museum of Natural History, University of Kansas, Lawrence 169:1-70.

Bennett, S.C. 2001. The osteology and functional morphology of the Late Cretaceous pterosaur Pteranodon. Part I. General descrip$\neg$ tion of osteology. Palaeontographica Abteilung A 260:1-112.

Bennett, S.C., and P. Penkalski. 2017. Waves of bone deposition on the rostrum of the pterosaur Pteranodon. In D.W.E. Hone, M.P. Witton, and D.M. Martill (eds). New Perspectives on Pterosaur Palaeobiology. Geological Society Special Publications 455: doi.org/10.1144/SP455.2.

Campos, D.A. and A.W.A. Kellner. 1997. Short note on the first occurrence of Tapejaridae in the Crato Member (Aptian), Santana Formation, Araripe Basin, Northeast Brazil. Anais da Academia Brasileira de Ciências, 69(1): 83-87.

Cheng, X., X. Jiang, X. Wang and A.W.A. Kellner. 2017. Premaxillary crest variation within the Wukongopteridae (Reptilia, Pterosauria) and comments on cranial structures in pterosaurs. Anais da Academia Brasileira de Ciencias 89(1):119-130.

Chiappe L. M, A.W.A. Kellner, D. Rivarola, S, Davila and M. Fox. 2000. Cranial morphology of Pterodaustro guinazui (Pterosauria: Pterodactyloidea) from the Lower Cretaceous of Argentina. Natural History Museum of Los Angeles County, Contributions in Science 483:1-19.

Chiappe L.M., D. Rivarola, E. Romero, S. Davila and L. Codorniu. 1998. Recent Advances in the paleontology of the Lower Cretaceous Lagarcito Formation (Parque Nacional Sierra de Las Quijadas, San Luis, Argentina). In S.G.Lucas, J.L. Kirkland, J.W. Estep (eds.). Lower and Middle Cretaceous Terrestrial Ecosystems, New Mexico: Museum of Natural History and Science Bulletin 14:187-192.

Codorniu L. and L.M. Chiappe. 2004. Early juvenile pterosaurs (Pterodactyloidea: Pterodaustro guinazui) from the Lower Cretaceous of central Argentina. Canadian Journal of Earth Sciences 41:9-18.

Dalla Vecchia F.M. 2009. Anatomy and systematics of the pterosaur Carniadactylus gen. n. rosenfeldi (Dalla Vecchia, 1995). Rivista Italiana di Paleontologia e Stratigrapfia 115(2):159-188.

Eaton, G.F. 1910. Osteology of Pteranodon. Memoirs of the Connecticut Academy of Arts and Sciences 2:1-38.

Frey E., D. M. Matill, and M.C. Buchy. 2003. A new crested ornithocheirid from the Lower Cretaceous of northeastern Brazil and the unusual death of an unusual pterosaur. In E. Buffetaut and J.M. Mazin (eds.). Evolution and Palaeobiology of Pterosaurs. Geological Society of London Special Publication 217:55-63.

Hattin, D. 1982. Stratigraphy and depositional environment of Smoky Hill Chalk Member, Niobrara (Upper Cretaceous) of the type area. Kansas Geological Survey Bulletin 225:1-108.
Harksen, J.C. 1966. Pteranodon sternbergi, a new fossil pterodactyl from the Niobrara Cretaceous Kansas. Proceedings of the South Dakota Academy of Science 45:74-77.

Hone D.W.A., S. Jiang and X. Xu. 2017. A taxonomic revision of Noripterus complicidens and Asian members of the Dsungaripteridae. In D.W.E. Hone, M.P. Witton, and D.M. Martill (eds). New Perspectives on Pterosaur Palaeobiology. Geological Society Special Publications 455: https://doi.org/10.1144/SP455.8

Kellner A.W.A. 2003. Pterosaur phylogeny and comments on the evolutionary history of the group. In E. Buffetaut and J.M. Mazin (eds.). Evolution and Palaeobiology of Pterosaurs. London: Geological Society Special Publication 217:105-137.

Kellner, A.W.A. 2010. Comments on the Pteranodontidae (Pterosauria, Pterodactyloidea) with the description of two new species. Anais da Academia Brasileira de Ciências 82:10631084. DOI 10.1590/S0001-37652010000400025

Kellner, A.W.A. 2015. Comments on Triassic pterosaurs with discussion about ontogeny and description of new taxa. Anais da Academia Brasileira de Ciencias 87(2):669-689 (doi: 10.1590/0001-3765201520150307).

Kellner, A.W.A. and D.A. Campos. 1988. Sobre um novo Pterossauro com crista sagital da Bacia do Araripe, Cretáceo Inferior do Nordeste do Brasil. Anais da Academia Brasileira de Ciências 60:459-469.

Kellner, A.W.A. and D.A. Campos. 2007. Short note on the ingroup relationships of the Tapejaridae (Pterosauria, Pterodactyloidea). Boletim do Museu Nacional - Geologia, 75:1-14

Kellner, A.W.A., D.A. Campos, J.M. Sayão, A.F.A. Saraiva, T. Rodrigues, G. Oliveira, L.A. Cruz, F.R. Costa, and H.P. Silva. 2013. The largest flying reptile from Gondwana: a new specimen of Tropeognathus cf. T. mesembrinus Wellnhofer, 1987 (Pterodactyloidea, Anhangueridae) and other large pterosaurs from the Romualdo Formation, Lower Cretaceous, Brazil. Anais da Academia Brasileira de Ciências, 85(1):113-135. doi: 10.1590/S0001-37652013000100009

Kellner, A.W.A. and Y. Tomida. 2000. Description of a new species of Anhangueridae (Pterodactyloidea) with comments on the pterosaur fauna from the Santana Formation (Aptian-Albian), Northeastern Brazil. National Science Museum Monographs 17:1-135.

Lü J. and Q. Ji. 2006. Preliminary results of a phylogenetic analysis of the pterosaurs from western Liaoning and surrounding areas. Journal of the Paleontological Society of Korea 22:239-261.

Lü J., D. Unwin, L. Xu and Z. Zhang. 2008. A new azhdarchoid pterosaur from the Lower Cretaceous of China and its implication for pterosaur phylogeny and evolution. Naturwissenschaften 95:891-897.

Manzig, P.C., A.W.A. Kellner, L.C. Weinschütz, C.E. Fragoso, C.S. Vega, G.B. Guimarães, L.C. Godoy, A. Liccardo, J.H.Z. Ricetti, and C.C. de Moura. 2014. Discovery of a rare pterosaur bone bed in a Cretaceous desert with insights on ontogeny and behavior of flying reptiles. PLOS ONE 9:e100005. DOI 10.1371/journal.pone.0100005 
Martill, D.M. and Naish, D. 2006. Cranial crest development in the azhdarchoid pterosaur Tupuxuara, with a review of the genus and tapejarid monophyly. Palaeontology 49:925-941. DOI 10.1111/j.1475-4983.2006.00575.x

Martin, J.E., J.L. Bertog, and D.C Parris. 2007. Revised lithostratigraphy of the lower Pierre Shale Group (Campanian) of central South Dakota, including newly designated members. In J.E Martin and D.C. Parris (eds.). The Geology and Paleontology of the Late Cretaceous Marine Deposits of the Dakotas. Geological Society of America Special Paper 427:9-21.

Martin-Silverstone, E.M., J.R.N. Glasier, J.H. Acorn, S. Mohr, and P.J. Currie. 2017. Reassesment of Dawndraco kanzai Kellner, 2010 and reassignment of the type specimen to Pteranodon sternbergi Harksen, 1966. Vertebrate Anatomy Morphology Palaeontology 3:47-59.

Martin-Silverstone, E.M., M.P. Witton, V.M. Arbour and P.J. Currie. 2016. A small azhdarchoid pterosaur from the latest Cretaceous, the age of flying giants. Royal Society Open Science 3: 160333. http://dx.doi.org/10.1098/rsos.160333

Miller, H.W. 1972. The taxonomy of the Pteranodon species from Kansas. Transactions of the Kansas Academy of Science 74:1-19.

Miller, H.W. 1978. Geosternbergia, a new name for Sternbergia Miller, 1972; Non Paulo Couto 1970; non Jordan, 1925. Journal of Paleontology 52:194.

Olson, E.C. 1957. Size-frequency distributions in samples of extinct organisms. Journal of Geology 65:309-333.

Padian, K., A. J. de Ricqles, and J. R. Horner. 1995. Bone histology determines identification of a new taxon of pterosaur (Reptilia: Archosauria). Comptes Rendus de l'Académie des Sciences, Paris (Sciences de la Vie) 320 (IIa):77-84.
Pinheiro F.L. and T. Rodrigues. 2017. Anhanguera taxonomy revisited: is our understanding of Santana Group pterosaur diversity biased by poor biological and stratigraphical control? PeerJ 5:e3285; DOI 10.7717/peerj.3285

Schoch R.M. 1984. Notes on the type specimens of Pteranodon and Nyctosaurus (Pterosauria, Pteranodontidae) in the Yale Peabody Museum collections. Postilla 194:1-23.

Vidovic S. and D.M. Martill. 2017. The taxonomy and phylogeny of Diopecephalus kochi (Wagner, 1837) and 'Germanodactylus rhamphastinus' (Wagner, 1851). In D.W.E.

Hone, M.P. Witton, and D.M. Martill (eds.). New Perspectives on Pterosaur Palaeobiology. Geological Society Special Publications 455: https://doi.org/10.1144/SP455.12

Wang, X., A.W.A. Kellner, S. Jiang and X. Cheng. 2012. New toothed flying reptile from Asia: close similarities between early Cretaceous pterosaur faunas from China and Brazil. Naturwissenschaften, 99:249-257 (doi 10.1007/s00114-0120889-1). ISSN 0028-1042.

Wang, X., A.W.A. Kellner, S. Jiang, Q. Wang, Y. Ma, Y. Paidoula, X. Cheng, T. Rodrigues, X. Meng, J. Zhang, N. Li, and Z. Zhou. 2014a. Sexually dimorphic tridimensionally preserved pterosaurs and their eggs from China. Current Biology 24:1323-1330. DOI 10.1016/j.cub.2014.04.054

Wang, X., T. Rodrigues, T., S. Jiang, X. Cheng and A.W.A. Kellner 2014b. An Early Cretaceous pterosaur with an unusual mandibular crest from China and a potential novel feeding strategy. Scientific Reports, 4:6329 (doi: 10.1038/srep06329).

Wang X. and Z.H. Zhou. 2006. Pterosaur assemblages of the Jehol Biota and their implication for the Early Cretaceous pterosaur radiation. Geologisches Jahrbuch 41:405-418. 